\title{
Community assembly, functional traits and phylogeny in Himalayan river birds
}

\author{
Ankita Sinha ${ }^{1}$, Nilanjan Chatterjee ${ }^{1}$, Ramesh Krishnamurthy ${ }^{1}$, and Stephen Ormerod $^{2}$ \\ ${ }^{1}$ Wildlife Institute of India \\ ${ }^{2}$ Cardiff University
}

February 3, 2022

\begin{abstract}
Heterogeneity in riverine habitats acts as a template for species evolution that influences river communities at different spatiotemporal scales. Although birds are conspicuous elements of these communities, the roles of phylogeny, functional traits and habitat character in their niche-use or species' assembly have seldom been investigated. We explored these themes by surveying multiple headwaters over $3000 \mathrm{~m}$ of elevation in the Himalayan Mountains of India where specialist river birds reach their greatest diversity on Earth. After ordinating community composition, species traits and habitat character, we investigated whether river-bird traits varied with elevation in ways that were constrained or independent of phylogeny, hypothesising that trait patterns reflect environmental filtering. Community composition and trait representation varied strongly with elevation and river naturalness as species that foraged in the river/riparian ecotone gave way to small insectivores with obligate links to the river channel. These trends were influenced strongly by phylogeny as communities became more clustered by functional traits at higher elevation. Phylogenetic signals varied among traits, however, and were reflected in body mass, bill size and tarsus length more than in body size, tail length and breeding strategy. These variations imply that community assembly in high altitude river birds reflects a blend of phylogenetic constraint and habitat filtering coupled with some proximate nichebased moulding of trait character. We suggest that the regional co-existence of river birds in the Himalaya is facilitated by the same array of factors that together reflect the highly heterogeneous template of river habitats provided by these mountain headwaters.
\end{abstract}

\section{Introduction}

Understanding how species assemble into communities is one of the most fundamental themes in ecology (Weiher et al. 2011; Götzenberger, et al. 2012; Gerhold et al. 2015). Key postulates are that evolutionary forces, environmental conditions and inter-species interactions combine to structure local communities (Cavender-Bares et al. 2009; Webb et al. 2002), with prominent theories proposing either neutral or deterministic processes (Swenson and Enquist 2009; Kembel 2010; Chase and Myers 2011). Neutral theory holds that species initially have quasi- identical requirements, and communities become structured by some dynamic balance between species loss through extinction, immigration and speciation through genetic drift (Kimura 1991). Conversely, niche-based concepts emphasize how environmental factors determine assembly through filtering mechanisms that limit the occurrence of species with similar traits (Kraft et al. 2015). While niche overlap - also known as limiting similarity - is expected to exclude similar species from co-existing (Macarthur and Levin 1975), environmental filtering and niche shifts act to moderate the extent to which similar species co-occur in similar habitat conditions (Weiher et al. 2011; Gerhold et al. 2015; Ulrich et al. 2018).

An important proviso in studying species and trait assembly in communities is that species relatedness should be controlled or represented in order to eliminate phylogeny as a potential confound (Mayfield and Levine, 2010; Kraft et al., 2015; Cadotte and Tucker, 2017). Phylogenetic analyses can account for trait expression at the species level thus enabling insights into the evolution of habitat preferences, species function and 
distribution patterns (Webb et al., 2002; McGill et al., 2006). Typical analyses attempt to understand whether ecologically relevant traits are conserved or modified along any given phylogeny thereby providing evidence about the roles environmental filtering and competitive segregation in assembly processes (Cavender-Bares et al. 2009; Pavoine et al. 2008; He et al. 2018; reviewed in Cadotte et al., 2017). Ideally, investigations aimed at understanding communities should blend field observations with some assessment of the functional and phylogenetic identities of the component species (McGill et al. 2006; Winemiller et al. 2015; Xu et al. 2017).

Given that ecosystem character changes in time and space, conditions under which species assemble and co-exist must also vary (McGill et al. 2006). Such environmental gradients offer a means to test competing assembly theories, for example by revealing relationships between environmental conditions and the morphological, physiological or behavioural traits of the species involved (Cavender-Bares et al. 2004; Dehling et al. 2014). Traits also reflect species' roles or functions within communities and can reveal mechanisms that affect distributional patterns along habitat gradients (Kraft et al. 2007). In terrestrial ecosystems, for example, competition, trait expression and environmental filtering along elevational gradients can have marked effects on bird communities (McCain 2009; Machac et al. 2011; Dehling et al. 2014; He et al. 2018; Ulrich et al. 2018; Ding et al. 2019; Chiu et al. 2020).

Among all ecosystems, rivers have received considerable emphasis in community ecology (Ward et al. 1998; Robinson et al. 2002; Altermatt et al. 2020), including seminal assessments of assembly rules, environmental filtering and trait-based studies (Poff 1997; Heino et al. 2015). In part, this interest reflects the pronounced environmental gradients represented by rivers both longitudinally and among contrasting river basins that together have created a diverse habitat template into which species have proliferated (Townsend and Hildrew 1994; Terui et al. 2021). Growing concern about the global status of freshwater ecosystems is also prompting interest in interactions between natural biodiversity patterns in rivers and the effects of environmental change (see Dudgeon et al. 2006).

So far, little of the research effort into community assembly has focussed on high-energy river systems in mountain landscapes, where large altitudinal ranges, complex topography and geomorphological dynamism give rise to pronounced ecological gradients with large species turnover (Ormerod et al. 1994; Jacobsen et al. 1997). Moreover, despite being conspicuous components of the global riverine fauna, river birds have been neglected in fundamental studies of mechanisms structuring communities, especially in mountainous areas (Manel et al. 2000; Sinha et al. 2019). One such region, the Himalayan Mountains, has the most diverse communities of specialist river birds on Earth (Buckton and Ormerod 2002) - thus prompting questions about evolutionary mechanisms that have allowed their coexistence. Marked diversity and distinctness in habitat use has led to some speculation about the roles of environmental filtering and niche partitioning, but there has been no formal analysis using current methods, and no attempts to assess phylogenetic effects in community assembly (Buckton and Ormerod 2008).

In this paper, we use specialist river birds to examine Southwood's original premise $(1977,1988)$, restated for rivers by Townsend \& Hildrew (1994), that habitats provide the templet through which evolutionary forces act with phylogeny to determine species' life-history. In turn, the resulting contrasts in species' traits act to determine how communities can contain multiple species while also influencing how communities change along environmental gradients. Specifically, we investigated river birds along multiple headstreams in the north-west Himalayan mountains of India, hypothesizing that river bird communities reflect detectable trait-environment relationships arising from environmental filtering. We asked (1) are there non-random patterns in species distribution and species' traits that reflect trait-environment relationships? and (2) are local species pools a result of common phylogenetic ancestry or convergence in response to environmental or biotic filters acting on regional communities? Addressing the first of these questions allowed us to quantify community change largely in relation to elevation while the second helped to identify how trait expression along this elevation gradient reflected filtering beyond the constraints of phylogeny.

\section{Materials and Methods}

\section{Study Area}


This particular study focussed on river-dependent birds along snow-fed and perennial headstreams in the western Himalaya of India, specifically the Bhagirathi and Amrutganga rivers in Uttarakhand, and the Tirthan river in Himachal Pradesh (Fig. S1). Sites were selected over an altitudinal gradient from 330 to 3100 and represented a range of habitat types from near-natural environments in protected areas to river stretches affected by human activities such as farming or urbanisation at lower altitude. Climatological conditions vary from sub-tropical to temperate (Mathur and Naithani 1999; Sinha, 2021), with drainage varying from glacial meltwater, rainwater and underground springs. Areas above $1500 \mathrm{~m}$ in the northwest Himalaya are highly seasonal with cold winters and mild summers (Barve, 2017).

Of the specific study locations, the Tirthan river ( $\left.\mathrm{N} 31.6396^{\circ} \mathrm{E} 77.401^{\circ}\right)$ is a major tributary of the river Beas in the Indus system. Here, survey locations encompassed river reaches between 1400- $2300 \mathrm{~m}$ in the Great Himalayan National Park Conservation Area in the Kullu district where the natural terrain is characterized by numerous high ridges, deep gorges, and narrow channels (Mathur and Naithani 1999). The buffer zone of the protected area has hamlets with orchards and other small scale agricultural practices and game fishing for introduced Brown Trout (Salmo trutta). Inside the protected area, the river flow is uninterrupted while the riparian zone is relatively pristine with conifers and broadleaf woodland. In the Gangetic headwaters, river reaches were sampled along the Bhagirathi $\left(\mathrm{N} 30.7564^{\circ} \mathrm{E} 78.5781^{\circ}\right)$ and its associated low-order tributaries covering an elevation gradient between 300-3300 m. Riparian vegetation consists of conifers at higher elevations and subtropical vegetation at the foothills. In this non-protected area within the administrative districts of Uttarkashi, Tehri and Dehradun, habitats have been modified by a range of anthropogenic pressures from agriculture and settlements (Sinha et al., 2019). Sites in the Amrutganga valley (N 30.466 $\left.{ }^{\circ} 079.269^{\circ}\right)$ are part of the Kedarnath Wildlife Division in Chamoli district where riparian land-use ranges from well vegetated river reaches to small villages with traditional agriculture (Barve 2017) between elevations of $1400 \mathrm{~m}$ to $2650 \mathrm{~m}$.

\section{Bird surveys}

Bird species that depend on aquatic production and occupy the riparian zone of Himalayan rivers were known from reconnaissance surveys and previous studies (Manel et al. 2000; Buckton \& Ormerod 2002). For the current analysis, replicate surveys of the 68 reaches were undertaken in 2017-2018 in the pre-monsoon period (March-June), thereby capturing the breeding season of almost all the target birds. The banks were walked by the same observer (AS) during early morning (06.00 to \pm 10.00$)$ and late afternoon (15.00 to \pm 18.00$)$ following a previously established field design in which three visits were made to each river segment of 500 $\mathrm{m}$ length on different days (Buckton 1998). This visit frequency is considered appropriate for detecting river obligate species that occupy linear territories (D'Amico and Hemery 2003). The order of visits to each site within the basin were randomized as far as possible while ensuring minimum distances of 30-50 km between the sampling sites on consecutive days to maintain spatial independence (McCarthy et al. 2013). Species were recorded as present if they were observed during any of the three visits, while numbers of individuals of each species were recorded on every visit and eventually converted to mean numbers per visit. Bird species occurring in less than five river reaches were excluded from further analysis.

\section{Trait information}

Data on species traits were obtained from existing literature and field surveys (2014 2019; Sinha 2021). Elevational distribution patterns were identified from surveys in both breeding and wintering seasons (Sinha 2021). Morphometric measurements such as body size, average body mass, bill length, wing span, tail length and tarsus length, along with clutch size and diet were gleaned from available literature (Ali and Ripley 1968; Buckton and Ormerod 2008). Birds were classified as 'obligate' and 'non-obligate' based on their dependence on the river or riparian zone for all of their life cycle activities such as feeding, breeding and roosting.

Any functional traits that were strongly intercorrelated ( $\mathrm{r}>0.7)$ were dropped from subsequent analysis to reduce multi-colinearity, while traits that summarised foraging and breeding behaviour were then retained in assessments of trait-environment relationships.

\section{River habitat characterization}


Physical variables describing the river and riparian zone at each site were recorded alongside bird surveys to capture information on river channel structure, flow character, bank structure, riparian vegetation and adjacent land use following methods developed by Sinha et al. (2019) after Raven et al. (1997). Observations were made at two different scales, respectively: (i) perpendicular transects or 'spot checks' at 10 points every $50 \mathrm{~m}$ along each $500 \mathrm{~m}$ reach specifically recording progressive lateral changes at each point in flow character and habitat features from the channel to the riparian zone; (ii) 'sweep up' assessments that recorded features over the whole $500 \mathrm{~m}$ survey site. The resulting data blended quantitative and semi-quantitative methods, for example with features recorded as present $(<33 \%$ of the survey reach) or extensive $(>33 \%)$, or on a sixpoint scale (rare:1-20\% cover; occasional 21-40\%; frequent 41-60\%; abundant 61-80\%; dominant 81-100\%). A more extensive description of the variables recorded and their ability to detect variations among locations is provided by Manel et al. (2000).

\section{Statistical analysis}

In outline, our statistical analysis involved i) ordination of species, trait and habitat variations along the large elevational range of our sites; ii) assessment of trends in taxonomic, phylogenetic and functional diversity; and iii) analysis of phylogenetic relatedness among the river species recorded to enable an unconfounded assessment of trait variations as community composition changed with environmental character.

\section{Community trends: RLQ analysis}

Trait and community responses to environmental gradients were ordinated using an RLQ framework, a multivariate technique that summarizes joint structure among matrices (Dray and Legendre 2008; Dray et al. 2014). In our case, these three matrix tables L (species distribution across river reaches surveyed as 15 species abundances*68 sites), R (environmental characteristics of samples: 68 sites*12 environmental variables) and Q (species traits: 15 species*8 traits) were analysed separately using different ordination methods in "ade4" package in R (Dray and Dufor 2007). The L-species table was analysed using Correspondence Analysis (CA), while the R-environmental variables table and Q-trait table were analysed by a Hill-Smith PCA combining quantitative and qualitative variables using CA species scores as a column weight to couple Q and L (Brown et al. 2014). In trait analysis, the RLQ approach crosses traits and environmental variables weighted by species abundances with significant effects tested using a two-step permutation procedure (25000 permutations). Model 2 permutes the rows of the $\mathrm{L}$ matrix to test the null hypothesis that no relationship exists between species abundance data with fixed traits and their environment; model 4 permutes the columns of dataset L to test the null hypothesis that species composition is not influenced by species traits given fixed environmental characteristics (Dray et al. 2014).

\section{Phylogenetic and functional trees}

As a basis for all subsequent phylogenetic analysis, we prepared a phylogenetic tree for the species in our community by trimming from the original phylogeny available from www.birdtree.org (Jetz et al. 2012; Fig. S2). Jetz et al. (2012) constructed this 'backbone tree' using genetic data from 6693 species of birds using 15 genes (19 loci) of 151 key species that were time-calibrated with ten well-known fossils (Jetz et al., 2012). We used the R packages "ape" and "phytools" (Paradis et al. 2004; Revell 2012) to obtain a consensus tree for our 15 target species using a pseudo-posterior distribution (https://birdtree.org/subsets/) from 1000 random samples from the 'backbone tree' after applying the $50 \%$ majority rule (i.e., the proportion of a split to be present in all trees) prior to modelling inter-specific variation across the phylogeny.

Bird species were classified into a functional tree using the quantitative morphological traits and qualitative feeding traits collected from Ali and Ripley (1968). We used "gower" distance to calculate the pair-wise distances between species while the UPGMA clustering method was used to convert the species-wise trait distances into branches in which the species formed the tips labelled with the aid of the "phangorn" package (Schliep 2011).

\section{Diversity metrics}

While species richness (SR) offered a simple measure of taxonomic diversity at each site, phylogenetic di- 
versity was calculated as Faith's phylogenetic diversity (PD) index, or the sum of all branch lengths of the phylogeny connecting all species at a site (Faith 1992), using the function 'pd' in R package picante (Kembel et al. 2010). The branch lengths are taken to represent evolutionary time, with higher PD indicating group of species that are more evolutionarily apart in time (Tucker et al. 2019). Absolute functional diversity was estimated as functional richness, FRic (Villéger et al. 2008), which represents the multidimensional volume of functional space occupied by the species within a community (Villéger et al. 2008). We estimated FRic by computing the pairwise distance between all birds (branch lengths of the functional dendrogram for species within a community) at every site which had more than two species. The dimensions of the functional distance matrix were condensed using PCoA to estimate the convex hull volume of functional spaces for species within a community in $\mathrm{R}$ using the package ' $F D$ ' (Laliberté et al. 2014).

Dispersion metrics for continuous traits were measured by quantifying the community-weighted mean (CWM) of traits showing phylogenetic signal using the 'dbFD' function in the 'FD' $\mathrm{R}$ package (Laliberté et al. 2014). The rationale behind this was that environmental filtering would lead to a decrease in trait range or variance in communities(e.g. Graham et al. 2012; Zhang et al. 2020).CWM statistics were calculated by taking averages of trait values of species that were present in each site (communities), weighted by species abundance.

Mean pairwise phylogenetic distance (MPD)and mean pairwise functional distance (MFD) at each site (Webb et al. 2002) were derived from the average functional or phylogenetic distance between each pair of species that co-existed at each site calculated as

$$
M P D(\text { or } M F D)=\frac{\sum_{i}^{n} \sum_{j}^{n} \delta_{i, j}}{n}(i \neq j)
$$

where $n$ is species richness in each band, $\delta_{i, j}$ is the pair-wise functional or phylogenetic distance (Euclidean distance) between species $i$ and species $j$.

For a phylogenetic or functional tree ' $\mathrm{T}$ ' with a set of species ' $n$ ' represented by a subset of branching nodes, the MPD of ' $n$ ' is equal to the average of the distances of all possible simple paths in ' $\mathrm{T}$ ' that connect pairs of nodes in ' $n$ '(Tsirogiannis and Sandel 2014). We compared these indices to 1000 randomized communities to test whether the functional and phylogenetic community structures differed from random expectations. For this we used the function 'ses. mpd' in package picante (Kembel et al. 2010) to generate random communities by shuffling the tips of the branches of the phylogenetic and functional trees used to calculate distance matrices for the entire community of river birds keeping the species richness constant. This procedure assumes that all species could colonize habitats across the whole gradient but are excluded due to local biotic and abiotic factors. We calculated the standardized effect size (SES) of MPD and MFD for each site comparing the observed values versus the expected values from the null communities (Kembel et al. 2010). The SES aids in inferring community assembly processes like environmental filtering and competition. When traits and lineages are conserved (i.e. with phylogenetic signals) with SES values $<0$, it indicates that communities are phylogenetically and functionally clustered and are shaped by environmental filtering. Community overdispersion with SES $>0$ for MPD and MFD values are taken to indicate competitive exclusion (Webb et al. 2002).

\section{Phylogenetic signal}

Among the available indices available to characterize phylogenetic signals in trait data, Blomberg's $K$ is the most widespread and is considered to capture the effect of trait evolution (Blomberg and Garland 2003; Münkemüller et al. 2012). This is based on an approach in which the magnitude of independent contrasts has smaller variance if related species are similar to each other in trait character. Observed versus expected contrast variances were compared under a null model created by swapping the tips of the phylogenetic tree to test for significance differences (Blomberg et al. 2003). When K approaches 1, trait evolution follows a mode of evolution that is consistent with Brownian motion (i.e. random walk), whereas for $\mathrm{K}>1$ and $<1$, respectively, close relatives are more similar or less similar than expected indicating a strong phylogenetic 
signal (Blomberg et al. 2003). Using all the traits measured as continuous variables (body mass, body size, bill length, tarsus length, and clutch size), we calculated Blomberg's $K$ as reported by Münkemüller et al. (2012) using the R package "phylosignal" (Keck et al. 2016). The significance of $K$ ( $p$-value) was calculated by comparison to a null distribution (Yang et al., 2014). We also used Moran's correlograms, plotted using the function "phyloCorrelogram" from the package "phylosignal" (Keck et al. 2016), to assess how phylogenetic autocorrelation changed across different phylogenetic distances. Originally a measure of spatial autocorrelation, when used in phylogenetic analysis Moran's I assesses phylogenetic proximity among species to describe the relationship between cross-taxonomic trait variation and phylogeny.

All statistical tests were performed with R software version 3.6.2 (R Core Team, 2019).

\section{Results}

\section{General species composition}

Field surveys recorded 483 individual birds belonging to 15 species from the families Alcedinidae, Motacillidae, Muscicapidae, Cinclidae, Ibidorynchidae and Charadridae. This included two river chats, three wagtails, two forktails, a thrush and a dipper which are all widespread in the Western Himalaya (Fig. S3). The Plumbeous water redstart (Rhyacornis fuliginosa) was the most abundant bird recorded in all the three river basins while Ibisbills (Ibidoryyncha struthersii) were recorded from just two river reaches in the Bhagirathi basin (Fig. S3). All 15 species were recorded from the Bhagirathi basins, while eight species were recorded in each of Amrut Ganga and Tirthan river basins. Sites with most species were from the Bhagirathi basin at elevations between $1000 \mathrm{~m}$ and $1500 \mathrm{~m}$ (Fig. S4).

\section{Community trends from RLQ analysis}

RLQ analysis illustrated how traits, species and habitat features varied together. Two axes explained $90.3 \%$ of the total inertia in the three tables, also accounting for most variability (>72-79\%) along the first two axes of the environmental variables (R-table) and species' functional traits (Q-table) separately (Table S1). Traits and environmental variables were particularly strongly related to the first RLQ axis (Fig. 1(a) and (b)).

Both major RLQ axes were related strongly to elevation. The first axis reflected a significant altitudinal trend towards narrower river stretches with faster flows, well vegetated banks and channels with boulders and pebbles while sandy banks, altered riparian cover, human settlements and human activities declined (Fig. 1(a)). Feeding traits correlated significantly with this axis as species using more terrestrial prey from the river margins increased towards higher elevations (e.g. Plumbeous Water Redstart; White-capped Water Redstart (Phoenicurus leucocephalus ) whereas species using a blend of terrestrial and aquatic prey declined (e.g White-throated Kingfisher (Halcyon smyrnensis ) (Fig. 1(b)). Simultaneously, species using aquatic prey solely such as the Brown Dipper (Cinclus pallasii) and Little Forktail(Enicurus scouleri) increased along this axis. Overall, the contribution of 'aquatic' feeding was minimal and neutral as aquatic-feeding species persisted at both ends of the axis.

The second axis of the RLQ mostly represented a significant decline in riparian vegetation cover and boulderstrewn banks but an increase in pebble banks and islands at higher elevation - typical of upland braided reaches. Bird traits varying significantly on this axis included an increase in clutch-size, but a decline in body size, tarsus size, bill size and aquatic/terrestrial foraging as species such as River Lapwing, Common Sandpiper (Actitis hypoleucos), Blue Whistling-thrush (Myophonus caeruleus) and Spotted Forktail(Enicurus maculatus) dropped out of the community (Fig. 1).

Strong, significant relationships among the trait, habitat and species abundance data were corroborated by the global RLQ permutation test ( $\mathrm{p}<0.001$ for model 2 of Dray et al. 2014). This held across all regions suggesting a uniform pattern in the species-trait-environment relationship at the community level. Model 2 was rejected $(\mathrm{p}=0.0005)$ and Model 4 accepted $(\mathrm{p}=0.608)$ together suggesting that $\mathrm{i})$ species distributions were influenced by environmental conditions, dominantly through changes related to elevation and ii) species composition reflected significant variations in trait character that also tracked elevation on both major axes. 


\section{Diversity gradients}

None of the three diversity indices (species richness, phylogenetic diversity (Faith's PD) and functional diversity (FRic) was related clearly to elevation and in all cases, there was substantial variation across sites (Fig. S4). After controlling for species richness, however, elevation affected phylogenetic composition such that communities at higher elevations $(>1000 \mathrm{~m})$ consisted of species that were more closely related than expected by chance (Fig. 2) - i.e., smaller-bodied river chats, forktails, wagtails and Brown Dipper. SES_MFD and SES_MPD also indicated that communities were functionally more clustered by traits and phylogeny at higher elevation, with this effect marginally weaker for functional $\left(R^{2}=0.43\right)$ than phylogenetic $\left(\mathrm{R}^{2}=0.47\right)$ composition (Fig. 2).

\section{Phylogenetic signal and traits}

In addition to the functional and phylogenetic clustering with increasing elevation, there was a significant phylogenetic signal in some of the functional traits of river birds as indicated by $\mathrm{K}$ and $\mathrm{K}^{*}$ values $(p<0.05)$ for body mass $(K=1.2332)$, bill size $(K=1.4098)$ and tarsus length $(K=1.0725)$ (Table 1$)$. In other words, similarities in these traits between species reflected strong phylogenetic effects. Among these three traits with a strong phylogenetic signal, community-weighted mean values for body mass and bill length declined with elevation, but there was no such effect in tarsus length (Fig. 3). In contrast, $\mathrm{K}$ values for body size, tail length and breeding traits indicated more substantial variation among related taxa, though only for body size was this effect formally significant (Table 1). Judged on Moran's I values, tarsus length and body mass had positive values while bill length had a negative autocorrelation with phylogenetic distance (Fig. S5).

\section{Discussion}

These data confirm the multifaceted changes in environmental conditions along Himalayan rivers over their large altitudinal range (Manel et al. 2001), in turn accompanied by pronounced variations in the community composition and trait character of river birds. Functional distances between co-existing species decreased with increasing elevation after controlling for species richness such that only a subset of traits persisted (Fig. 2). Communities at higher altitudes shifted towards species with smaller bodies, shorter tarsi, smaller bills and a greater tendency to feed as insectivores in the ripariang zone or on aquatic prey. These patterns are consistent with the hypothesis that altitudinal trends affect these communities through environmental filtering (Dehling et al. 2014; Vollstädt et al. 2017; Hanz et al. 2019). They also echo similar filtering effects for example, on ground beetles along a land disturbance gradient (Ribera et al. 2001), plants along a salinity gradient (Pavoine et al. 2011), ants along a complexity gradient (Weischer et al. 2012), bats across a gradient of forest fragmentation (Farneda et al. 2015) and birds with urbanization (Evans et al. 2018). Beyond these filtering effects, however, phylogenetic dispersion also declined with increasing altitude, illustrating for the first time that bird species composition along Himalayan rivers is constrained by phylogenetic origins: passerines, and specifically muscicapids or their near-relatives, dominated higher altitude rivers.

A range of caveats affect interpretation in studies like ours where survey data are used to test hypotheses. Above all, the evolutionary phenomena implied in our analyses occur over temporal and spatial scales that preclude straightforward experimentation. Large-scale surveys of this type provide one of the few pragmatic methods of capturing large-scale phenomena, but need appropriate design to eliminate potential confounds as well as data that corroborate the ecological or evolutionary processes inferred from correlations (Manel et al. 2000). In support of our approach, our design involved surveys that were replicated across regions, and observations that we took as robust representations of past evolutionary processes - such as phylogenetic relatedness or trait expression. Nevertheless, there are well-known challenges in understanding how trait data or phylogenies reflect ecological processes (Cadotte et al. 2019). Furthermore, functional approaches fail to account for within-species variations across populations while the phylogenetic approach can inflate signals related to certain traits (Zhao et al. 2020). At a more empirical level, some parts of our analysis would have been improved by more detailed data. Feeding traits, for example, were represented only crudely by categorisations of prey use, yet river birds can make precise selection for different prey types when foraging. This includes targeting prey of specific size, elemental composition, accessibility and ease of handling 
(Ormerod and Tyler 1991a). Potentially even more important in the context of niche use and limiting similarity is the extent to which riparian and river birds in the Himalayan mountains use subtly different components of the available prey base. This is apparent among the common insectivores whose diet appears to be partitioned along dimensions of prey size, taxonomic composition and capture method (aerial vs terrestrial vs aquatic) (Buckton and Ormerod 2008). However, incomplete dietary information from several of the species in our study precluded more detailed dietary assessment. In similar vein, measurements of the availability or abundance of prey used by any of the species were beyond the capabilities of this study even though prey abundance is known to influence the density of river birds (Ormerod 1985; Ormerod and Tyler 1991b). A further limitation is that both our field surveys and data analysis focussed on the breeding season, yet several of the species in our study are altitudinal migrants that descend to lower elevations in winter. As a consequence, our investigation is likely to have reflected evolutionary effects during the breeding period when resources demands and selection pressures are likely to be large (Verhulst and Nilsson 2008).

Notwithstanding these caveats, our study revealed clear relationships among river character, species traits and community composition of river birds in the Himalayan mountains aided by the increasingly used RLQ analysis (Ribera et al. 2001). Here, over the largest altitudinal range on Earth, species composition and trait representation changed dramatically as several species of kingfishers, River Lapwing, Common Sandpiper, Blue Whistling-thrush and Spotted Forktail gave way at higher altitude to a generally smaller, insectivorous and functionally clustered array of species such as Plumbeous Water Redstart, White-capped Water Redstart, Brown Dipper and Little Forktail. The latter group of passerines that breed along high elevation river reaches come from several genera (Fig. 1(c)) and are morphologically adapted for different foraging techniques such as fly catching, ground gleaning and aquatic foraging in aquatic, bankside and riparian habitats. Besides tracking the trends in habitat structure and vegetation pattern assessed here, these community changes also reflect well known altitudinal trends in temperature, nutrient status, oxygen concentrations, discharge patterns and sediment regimes that have major effects on fish densities, invertebrate abundances and other factors influencing prey availability (Ormerod et al. 1994). The resulting heterogeneity in habitat character and productivity in this region has given rise to the greatest diversity of specialist river birds on Earth in which selective habitat use, foraging methods and niche partitioning are consistent with resource segregation (Buckton and Ormerod, 2002; 2008). These established patterns add to the support from our data for the hypothesis that river habitat templates have influenced trait distributions within river bird communities through the evolutionary history of the species involved.

In addition to major altitudinal trends in community composition and trait expression among Himalayan river birds, we found that species were assembled non-randomly along the elevation gradient into communities with distinct phylogenetic origins and functional character. Although reflecting patterns among a small group of species, the strength of this phylogenetic signal implies that historical contingency has influenced trait-environment relationships and river bird communities in the Himalaya, particularly at high altitude. It is particularly noteworthy that three of the four species most abundant at high altitudes were Muscicapidae - Plumbeous Water Redstart, White-capped Water Redstart and Little Forktail - an Old-World family with large richness across the Himalayan region in general (Sinha 2021). When communities of organisms are shaped predominantly by environmental conditions, their composition is typically aggregated by similar trait compositions in similar habitats, irrespective of evolutionary history or phylogenetic relatedness (Southwood 1977, Poff 1997). This contrasts with our case where a strong phylogenetic signal in composition and functional traits reflected circumstances where related species co-occurred because of shared environmental requirements, similar general morphology and behavioural character (Webb et al. 2002). Assuming that trait values (body mass, bill length and tarsus length) reflected niche occupancy, the strong phylogenetic signals in our data suggest that functional traits and niche occupancy were constrained by phylogeny, at least at higher elevation. Interestingly, however, some aspects of trait expression departed from the expectations of phylogenetic effects more than others: phylogeny was reflected in body mass, bill size and tarsus length more than in body size, tail length and breeding traits (Table 1). We suggest that community assembly in high altitude river birds must therefore reflect a blend of phylogenetic constraint and habitat filtering coupled with some proximate niche-based selection of trait character for specialization (Reif et al. 2015; 
Morelli et al.2019). This effect is particularly well illustrated in the forktails (Enicurus spp.), in which tail length in the Little Forktail is substantially reduced in comparison to its congeners and potentially linked to its highly specialised foraging niche around the splash zone of large boulders in highly turbulent flows (Buckton and Ormerod 2008). Similarly, White-capped Water Redstart and Plumbeous Redstart contrast in body size, with smaller size in the latter potentially facilitating energy efficiency in its extensive use of aerial foraging. Further detailed assessments of trait expression and function among Himalayan river birds would prove interesting.

\section{Broader implications: conservation and environmental change}

As well as their relevance to evolutionary influences on river birds over the large altitudinal range of the Himalayan Mountains, our findings have broader implications for biodiversity conservation. Human impacts on rivers tend to simplify structural complexity, reduce connectivity and impair water quality, and across the world these processes are contributing to the decline or elimination of specialist organisms and population reductions that are among the fastest of any global ecosystem (Evans et al. 2018; Bower and Winemiller 2019; Tickner et al. 2020). These effects arise because river catchment ecosystems are both hotpots for biological diversity and hotspots for resource exploitation (Strayer and Dudgeon 2010). Both these factors have parallels with our data. First, at a global level, the association between overall bird richness and habitat heterogeneity is a well-known phenomenon, especially for species that are specialized for particular habitat types - in this case high-energy rivers (Robinson et al. 2002; Larsen et al. 2010). Specialist river birds have developed unparalleled richness and niche specificity in the Himalaya reflecting both the complex relief and productivity in this region so that major habitat impairment could have effects of global significance (Buckton and Ormerod 2002). Secondly, these same river environments face multiple pressures, for example, from climate change, catchment conversion to agriculture, pollution, hydropower and water-resource exploitation (Manel et al. 2000; Sinha et al. 2019). Some species in our study were associated with the least modified river reaches where bank vegetation, geomorphological structure and flow patterns were unimpaired and expected to support abundant prey (Ormerod and Tyler 1987,1991b; Sinha et al. 2019). Possible effects of habitat modification were also apparent in the different river basins surveyed, for example where river reaches in the Bhagirathi basin were modified for hydropower development (Fig.1 (a)). If our interpretation is correct - that riparian and riverine habitat features act as environmental filters that structure river bird assemblages locally - it is likely that anthropogenic effects on rivers will modify these filtering processes and alter community composition unless checked by conservation action. Particular phylogenetic groups of species are at risk.

\section{Conclusion}

Overall, these data have both regional and general significance. Regionally, they provide explanations for changing community composition and trait expression in Himalayan rivers. More generally, they expand the understanding of how trait distributions and assemblages are the result of a complex interplay between trait filtering along environmental gradients coupled with evolutionary processes. There exists a clear phylogenetic imprint that contributes to contemporary species-trait-habitat relations in river bird assemblages in the Himalayan Mountains. In the light of large - scale human alterations to the biosphere, represented particularly strongly in rivers, models of trait-environment relationships like ours can be instrumental in predicting future range shifts in the distribution of species and traits. Our study reiterates that the simultaneous assessment of phylogenetic relatedness among co-existing species with trait-habitat analyses can benefit the understanding of species assembly patterns across regional fauna.

\section{Literature cited}

Adams, DC (2014). A generalized K statistic for estimating phylogenetic signal from shape and other highdimensional multivariate data. Syst biol, 63(5), 685-697.

Ali S, Ripley, SD (1968) The Handbook of Birds of India and Pakistan. Ten volumes.

Altermatt F, Little CJ, Maechler E, Wang S, Zhang X, Blackman RC (2020). Uncovering the complete 
biodiversity structure in spatial networks: the example of riverine systems. Oikos, 129(5), 607-618.

Barve SS, (2017). Hypoxia, Habitats and Competition: Determinants of Elevational Distribution in Himalayan Birds (Doctoral dissertation, Cornell University).

Blomberg SP, Garland TJ, Ives AR (2003). Testing for phylogenetic signal in comparative data: Behavioural traits are more labile. Evolution 57: 717-745.

Bower LM, \& Winemiller KO (2019). Fish assemblage convergence along stream environmental gradients: An intercontinental analysis. Ecography, 42: 1691-1702.

Brown AM, Warton DI, Andrew NR, Binns M, Cassis G, \& Gibb H (2014). The fourth-corner solution-using predictive models to understand how species traits interact with the environment. Methods Ecol Evol, 5: 344-352.

Buckton ST, Ormerod, SJ (2002) Global patterns of diversity among the specialist birds of riverine landscapes. Freshwater Biol 47:695.

Buckton ST, Ormerod SJ (2008) Niche segregation of Himalayan river birds. J Field Ornithol, 79: 176-185.

Cadotte MW,Tucker CM (2017) Should environmental filtering be abandoned? Trends Ecol Evol 32: 429-437.

Cadotte M W, Carboni M, Si X, Tatsumi S (2019) Do traits and phylogeny support congruent community diversity patterns and assembly inferences? J Ecol 107: 2065-2077.

Cavender-Bares J, Kitajima K, Bazzaz FA (2004) Multiple trait associations in relation to habitat differentiation among 17 Floridian oak species. Ecol Monogr 74: 635-662.

Cavender-Bares, J., Kozak, K. H., Fine, P. V., \& Kembel, S. W. (2009). The merging of community ecology and phylogenetic biology. Ecol Lett, 12(7), 693-715.

Chase JM, Myers JA (2011). Disentangling the importance of ecological niches from stochastic processes across scales. Philos T Roy Soc B, 366(1576), 2351-2363.

Chiu MC, Ao S, He F, Resh VH, Cai Q (2020) Elevation shapes biodiversity patterns through metacommunity-structuring processes. Sci Total Environ 743: 140548.

D'Amico F, Hemery G (2003). Calculating census efficiency for river birds: a case study with the Whitethroated Dipper Cinclus cinclus in the Pyrenees. Ibis 145: 83-86.

Dehling, DM, Fritz, SA, Topfer T, Packert M, Estler P, Bohning-Gaese K, Schleuning M (2014). Functional and phylogenetic diversity and assemblage structure of frugivorous birds along an elevational gradient in the tropical Andes. Ecography 37: 1047-1055.

Ding Y, Zang R, Lu X, Huang J, Xu Y (2019) The effect of environmental filtering on variation in functional diversity along a tropical elevational gradient. J Veg Sci 30: 973-983.

Dray S, Dufour A (2007) "The ade4 Package: Implementing the Duality Diagram for Ecologists." J Stat Softw 22: $1-20$.

Dray S, Legendre P (2008). Testing the species traits-environment relationships: the fourth-corner problem revisited. Ecology 89: 3400-3412.

Dray S, Choler P, Doledec S, Peres-Neto PR, Thuiller W, Pavoine S, terBraak CJ (2014) Combining the fourth-corner and the RLQ methods for assessing trait responses to environmental variation. Ecology 95: $14-21$.

Dudgeon D, Arthington AH, Gessner MO, Kawabata ZI, Knowler DJ, Leveque C, Naiman RJ, PrieurRichard AH, Soto D, Stiassny ML, Sullivan CA (2006). Freshwater biodiversity: importance, threats, status and conservation challenges. Biol Rev 81: 163-182. 
Evans BS, Reitsma R, Hurlbert AH, Marra, PP (2018). Environmental filtering of avian communities along a rural-to-urban gradient in Greater Washington, DC, USA. Ecosphere 9: e02402.

Faith DP (1992). Conservation evaluation and phylogenetic diversity. Biol Conserv 61: 1-10.

Fargione J, Brown CS, Tilman D (2003). Community assembly and invasion: an experimental test of neutral versus niche processes. P Natl Acad Sci 100: 8916-8920.

Farneda FZ, Rocha R, Lopez-Baucells A, Groenenberg M, Silva I, Palmeirim JM, Bobrowiec PE Meyer CF (2015) Trait-related responses to habitat fragmentation in Amazonian bats. J Appl Ecol 52: 1381-1391.

Gerhold P, Cahill JF, Winter M, Bartish IV, Prinzing A (2015) Phylogenetic patterns are not proxies of community assembly mechanisms (they are far better). Funct Ecol 29: 600-614.

Gotzenberger L, de Bello F, Brathen KA, Davison J, Dubuis A, Guisan A, Lepš J, Lindborg R, Moora M, Pärtel M, Pellissier L (2012) Ecological assembly rules in plant communities-approaches, patterns and prospects. Biol Rev 87: 111-127.

Graham CH, Parra JL, Rahbek C, McGuire JA (2009) Phylogenetic structure in tropical hummingbird communities. P Natl Acad Sci 106: 19673-19678.

Grytnes JA,Vetaas OR (2002) Species richness and altitude: a comparison between null models and interpolated plant species richness along the Himalayan altitudinal gradient, Nepal. Am Nat 159: 294-304.

Hanz DM, Böhning-Gaese, K, Ferger SW, Fritz SA, Neuschulz EL, Quitian M, Santillan V, Topfer T, Schleuning M (2019) Functional and phylogenetic diversity of bird assemblages are filtered by different biotic factors on tropical mountains. J Biogeogr 46: 291-303.

He X, Luo K, Brown C, Lin L (2018) A taxonomic, functional, and phylogenetic perspective on the community assembly of passerine birds along an elevational gradient in southwest China. Ecol Evol 8: 2712-2720.

Heino J, Soininen J, Alahuhta J, Lappalainen J, Virtanen R (2015) A comparative analysis of metacommunity types in the freshwater realm. Ecol Evol 5: 1525-1537.

Jacobsen D, Schultz R, Encalada A (1997) Structure and diversity of stream invertebrate assemblages: the influence of temperature with altitude and latitude. Freshwater Biol 38: 247-261.

Jetz W, Thomas GH, Joy JB, Hartmann K, Mooers AO (2012) The global diversity of birds in space and time. Nature 491: 444-448.

Kembel SW (2009) Disentangling niche and neutral influences on community assembly: assessing the performance of community phylogenetic structure tests. Ecol Lett 12: 949-960.

Kembel SW (2010) An introduction to the picante package. Retrieved from picante. r-forge. r-project. org/picante-intro. pdf.

Keck F, Rimet F, Bouchez A, Franc A (2016) phylosignal: an R package to measure, test, and explore the phylogenetic signal. Ecol Evol 6: 2774-2780.

Kraft NJ, Cornwell WK, Webb CO, Ackerly DD (2007) Trait evolution, community assembly, and the phylogenetic structure of ecological communities. Am Nat 170: 271-283.

Kraft NJ, Adler PB, Godoy O, James EC, Fuller S, Levine JM (2015). Community assembly, coexistence and the environmental filtering metaphor. Functl Ecol 29: 592-599.

Laliberte E, Legendre P, Shipley B, Laliberte ME (2014) Package 'FD'. Measuring functional diversity from multiple traits, and other tools for functional ecology. Available at: http://cran.rproject.org/web/packages/FD/ (accessed 12 August 2017).

Larsen S, Sorace A, Mancini L (2010) Riparian bird communities as indicators of human impacts along Mediterranean streams. Environ Manage 45: 261-273. 
Manel S, Buckton ST, Ormerod SJ (2000) Testing large-scale hypotheses using surveys: the effects of land use on the habitats, invertebrates and birds of Himalayan rivers. J Appl Ecol 37: 756-770.

Martinez AE, Gomez JP, Ponciano JM, Robinson SK (2016) Functional traits, flocking propensity, and perceived predation risk in an Amazonian understory bird community. Am Nat 187: 607-619.

Mathur VB, Naithani S (1999) Development of a Spatial Database of the Great Himalayan National Park Conservation Area (GHNPCA) in GIS Domain. Wildlife Institute of India, Dehradun, India.

Mayfield MM, Levine JM (2010) Opposing effects of competitive exclusion on the phylogenetic structure of communities. Ecol Lett 13: 1085-1093.

McCarthy MA, Moore JL, Morris WK, Parris KM, Garrard GE, Vesk PA, Rumpff L, Giljohann KM, Camac JS, Bau SS, Friend T (2013) The influence of abundance on detectability. Oikos 122: 717-726.

McCain CM (2009) Global analysis of bird elevational diversity. Global Ecol Biogeogr 18: 346-360.

McGill BJ, Enquist BJ, Weiher E, Westoby M (2006) Rebuilding community ecology from functional traits. Trends Ecol Evol 21: 178-185.

Morelli F, Benedetti Y, Moller AP, Fuller RA (2019) Measuring avian specialization. Ecol Evol 9: 8378-8386.

Munkemuller T, Lavergne S, Bzeznik B, Dray S, Jombart T, Schiffers K, Thuiller W (2012) How to measure and test phylogenetic signal. Methods Ecol Evol 3: 743-756.

Ormerod SJ (1985) The diet of breeding dippers Cinclus cinclus and their nestlings in the catchment of the River Wye, mid-Wales: A preliminary study by faecal analysis. Ibis 127: 316-331.

Ormerod SJ, Tyler SJ (1987) Aspects of the breeding ecology of Welsh Grey Wagtails Motacilla cinerea . Bird Study 34: 43-51.

Ormerod SJ, Tyler SJ (1991) Exploitation of prey by a river bird, the dipper Cinclus cinclus (L.), along acidic and circumneutral streams in upland Wales. Freshwater Biol 25: 105-116.

Ormerod SJ, O'Halloran J, Gribbin SD, Tyler SJ (1991) The ecology of dippers Cinclus cinclus in relation to stream acidity in upland Wales: breeding performance, calcium physiology and nestling growth. J Appl Ecol 419-433.

Ormerod SJ, Rundle SD, Wilkinson SM, Daly GP, Dale KM, Juttner I (1994) Altitudinal trends in the diatoms, bryophytes, macroinvertebrates and fish of a Nepalese river system. Freshwater Biol 32: 309-322.

Ormerod SJ, Dobson M, Hildrew AG, Townsend C (2010) Multiple stressors in freshwater ecosystems. Freshwater Biol 55: 1-4.

Paradis E, Claude J, Strimmer K (2004) APE: analyses of phylogenetics and evolution in R language. Bioinformatics 20: 289-290.

Pavoine S, Ollier S, Pontier D, Chessel D (2008) Testing for phylogenetic signal in phenotypic traits: new matrices of phylogenetic proximities. Theor Popul Biol 73: 79-91.

Pavoine S, Vela E, Gachet S, De Belair G, Bonsall MB (2011) Linking patterns in phylogeny, traits, abiotic variables and space: a novel approach to linking environmental filtering and plant community assembly. J Ecol 99: 165-175.

Price TD, Qvarnstrom A, Irwin DE (2003) The role of phenotypic plasticity in driving genetic evolution. Philos T Roy Soc B, 270: 1433-1440.

Price TD, Hooper DM, Buchanan CD, Johansson US, Tietze DT, Alstrom P, Olsson U, Ghosh-Harihar M, Ishtiaq F, Gupta SK Mohan D (2014) Niche filling slows the diversification of Himalayan songbirds. Nature 509: $222-225$. 
Poff NL (1997) Landscape filters and species traits: towards mechanistic understanding and prediction in stream ecology. J N Am Benthol Soc 16: 391-409.

Reif J, Hořák D, Krištín A, Kopsová L, Devictor V (2016) Linking habitat specialization with species' traits in European birds. Oikos 125: 405-413.

Revell LJ (2012) phytools: an R package for phylogenetic comparative biology (and other things). Methods Ecol Evol 3: 217-223.

Ribera I, Dolédec S, Downie IS, Foster GN (2001) Effect of land disturbance and stress on species traits of ground beetle assemblages. Ecology 82: 1112-1129.

Ryo M, Harvey E, Robinson CT, Altermatt F (2018) Nonlinear higher order abiotic interactions explain riverine biodiversity. J Biogeogr 45: 628-639.

Schliep KP (2011) phangorn: phylogenetic analysis in R. Bioinformatics 27: 592-593.

Sinha A, Chatterjee N, Ormerod SJ, Adhikari BS, Krishnamurthy R (2019) River birds as potential indicators of local-and catchment-scale influences on Himalayan river ecosystems. Ecosyst People 15: 90-101.

Sinha A (2021) Patterns of distribution and multi-scale habitat correlates of riverine birds in the upper Ganges, Western Himalaya. Western Himalaya (Doctoral dissertation, Wildlife Institute of India, Saurashtra University, Rajkot, India).

Southwood TR (1977) Habitat, the templet for ecological strategies? J Anim Ecol 46: 337-365.

Southwood, T. R. (1988). Tactics, strategies and templets. Oikos 3-18.

Strayer DL, Dudgeon D (2010) Freshwater biodiversity conservation: recent progress and future challenges. J N Am Benthol Soc 29: 344-358.

Swenson NG, Enquist BJ (2009) Opposing assembly mechanisms in a Neotropical dry forest: implications for phylogenetic and functional community ecology. Ecology 90: 2161-2170.

Terui A, Kim S, Dolph CI, Kadoya T, Miyazaki Y (2021) Emergent dual scaling of riverine biodiversity. P Natl Acad Sci 118: e2105574118.

Townsend CR, Hildrew AG (1994) Species traits in relation to a habitat templet for river systems. Freshwater Biol 31: 265-275.

Tickner D, Opperman JJ, Abell R, Acreman M, Arthington AH, Bunn SE, Cooke SJ, Dalton J, Darwall W, Edwards G, Harrison I, Hughes K, Jones T, Leclère D, Lynch AJ, Leonard P, McClain ME, Muruven D, Olden JD, Ormerod SJ, Robinson J, Tharme RE, Thieme M, Tockner K, Wright M. Young L (2020) Bending the curve of global freshwater biodiversity loss: an emergency recovery plan. BioScience 70: 330-342.

Tsirogiannis C, Sandel B (2014) Computing the skewness of the phylogenetic mean pairwise distance in linear time. Algorithm Mol Biol 9: 1-16.

Tucker CM, Aze T, Cadotte MW, Cantalapiedra JL, Chisholm C, Díaz S, Grenyer R, Huang D, Mazel F, Pearse WD, Pennell MW, Winter M, Mooer AO (2019) Assessing the utility of conserving evolutionary history. Biol Rev 94: 1740-1760.

Ulrich W, Banks-Leite C, De Coster G, Habel JC, Matheve H, Newmark WD, Tobias JA, Lens L (2018) Environmentally and behaviourally mediated co-occurrence of functional traits in bird communities of tropical forest fragments. Oikos 127: 274-284.

Verhulst S, Nilsson J (2008) The timing of birds' breeding seasons: a review of experiments that manipulated timing of breeding. Philos T Roy Soc B 363: 399-410. 
Vollstadt MG, Ferger SW, Hemp A, Howell KM, Topfer T, Bohning-Gaes K, Schleuning M (2017) Direct and indirect effects of climate, human disturbance and plant traits on avian functional diversity. Global Ecol Biogeogr 26: 963-972.

Villeger S, Mason NW, Mouillot D (2008) New multidimensional functional diversity indices for a multifaceted framework in functional ecology. Ecology 89: 2290-2301.

Webb CO, Ackerly DD, McPeek MA, Donoghue MJ (2002) Phylogenies and community ecology. Annu Rev Ecol Syst 33: 475-505.

Weiher E, Freund D, Bunton T, Stefanski A, Lee T, Bentivenga S (2011) Advances, challenges and a developing synthesis of ecological community assembly theory. Philos T Roy Soc B 366: 2403-2413.

Winemiller KO, Fitzgerald DB, Bower LM, Pianka ER (2015) Functional traits, convergent evolution, and periodic tables of niches. Ecol Lett 18: 737-751.

Xu J, Chen Y, Zhang L, Chai Y, Wang M, Guo Y, Li T, Yue M (2017) Using phylogeny and functional traits for assessing community assembly along environmental gradients: A deterministic process driven by elevation. Ecol Evol 7: 5056-5069.

Zhao Y, Dunn RR, Zhou H, Si X, Ding P (2020) Island area, not isolation, drives taxonomic, phylogenetic and functional diversity of ants on land-bridge islands. J Biogeogr 47: 1627-1637.

Zhang Q, Holyoak M, Chen C, Liu Z, Liu J, Che X, Zou, F (2020) Trait-mediated filtering drives contrasting patterns of species richness and functional diversity across montane bird assemblages. J Biogeogr 47: 301312.

TABLE 1. Traits used to measure functional diversity and phylogenetic signals among breeding river birds in the Western Himalaya, India. The table gives Blomberg's K values with significance values (in parentheses).

\begin{tabular}{lll}
\hline Trait & Blomberg's $K$ & $K^{*}$ \\
\hline Body mass (g) & $1.23(0.004)$ & $1.13(0.009)$ \\
$\begin{array}{l}\text { Body size (mm) } \\
\text { Breeding months (number of }\end{array}$ & $0.68(0.01)$ & $0.63(0.018)$ \\
months) & $0.39(0.172)$ & $0.43(0.167)$ \\
$\begin{array}{l}\text { Clutch size (maximum number } \\
\text { of eggs) }\end{array}$ & $0.54(0.027)$ & $0.60(0.023)$ \\
Bill length (mm) (from skull) & $1.41(0.001)$ & $1.38(0.001)$ \\
Tail length (mm) & $0.28(0.283)$ & $0.31(0.259)$ \\
Tarsus length (mm) & $1.16(0.003)$ & $1.16(0.008)$ \\
\hline
\end{tabular}

\section{Figure legends}

Figure 1. Biplot depicting the first two axes of the RLQ multivariate analysis. Axes and scale are same for figures all plots which represent projections in the plane of the first two main components of (a) environmental variables, (b) species traits and (c) bird species.

Figure 2. Plots showing elevational trends of standard effect size of mean phylogenetic distance (SES_MPD) and standard effect size of mean functional distance (SES_MFD) of breeding river birds across the $\overline{6} 8$ river reaches in the western Himalaya.

Figure 3. Trends of community weighted mean (CWM) values for the three functional traits (body-mass, bill-size and tarsus length) of river-bird communities from different river basins plotted along the elevation gradient. The straight lines were fitted with a linear regression model and the $\mathrm{R}^{2}$ values and $\mathrm{p}$ values are listed in each figure. 
Data accessibility statement: The data that support the findings of this study will be made openly available in open data repository (e.g "figshare") upon acceptance of the manuscript.

Competing interest statement : The authors have no conflict of interest to declare.

Author contribution section: AS, NC, KR and SJO conceived the study. AS collected the data, KR facilitated the field permits, NC and AS analyzed the data. AS, SJO, KR and NC wrote the manuscript. All authors read and reviewed the final manuscript

\section{Acknowledgements}

The authors thank the National Mission on Himalayan Studies (Wildlife Institute of India, Dehardun and G. B. Pant Institute of Himalayan Environment, Almora, Ministry of Environment, Forest and Climate Change for providing the funds to AS to carry out this study. We thank the Director, Dean and Dr. S. Sathyakumar for facilitating the NMHS fellowship programme at the Wildlife Institute of India. We thank Dr. B. S. Adhikari for facilitating logistics for the Amrut Ganga field surveys and Hima Nair, Meghna Bandopadhyay, Jaswant Singh, Kuwar Singh, Manish Bisht, and others who helped in the field. We thank Dr. Fredric Windsor for providing valuable inputs during multiple stages of the study. Local residents of Bhagirathi and Tirthan valley and Mandal village are thanked for their support during field surveys. 

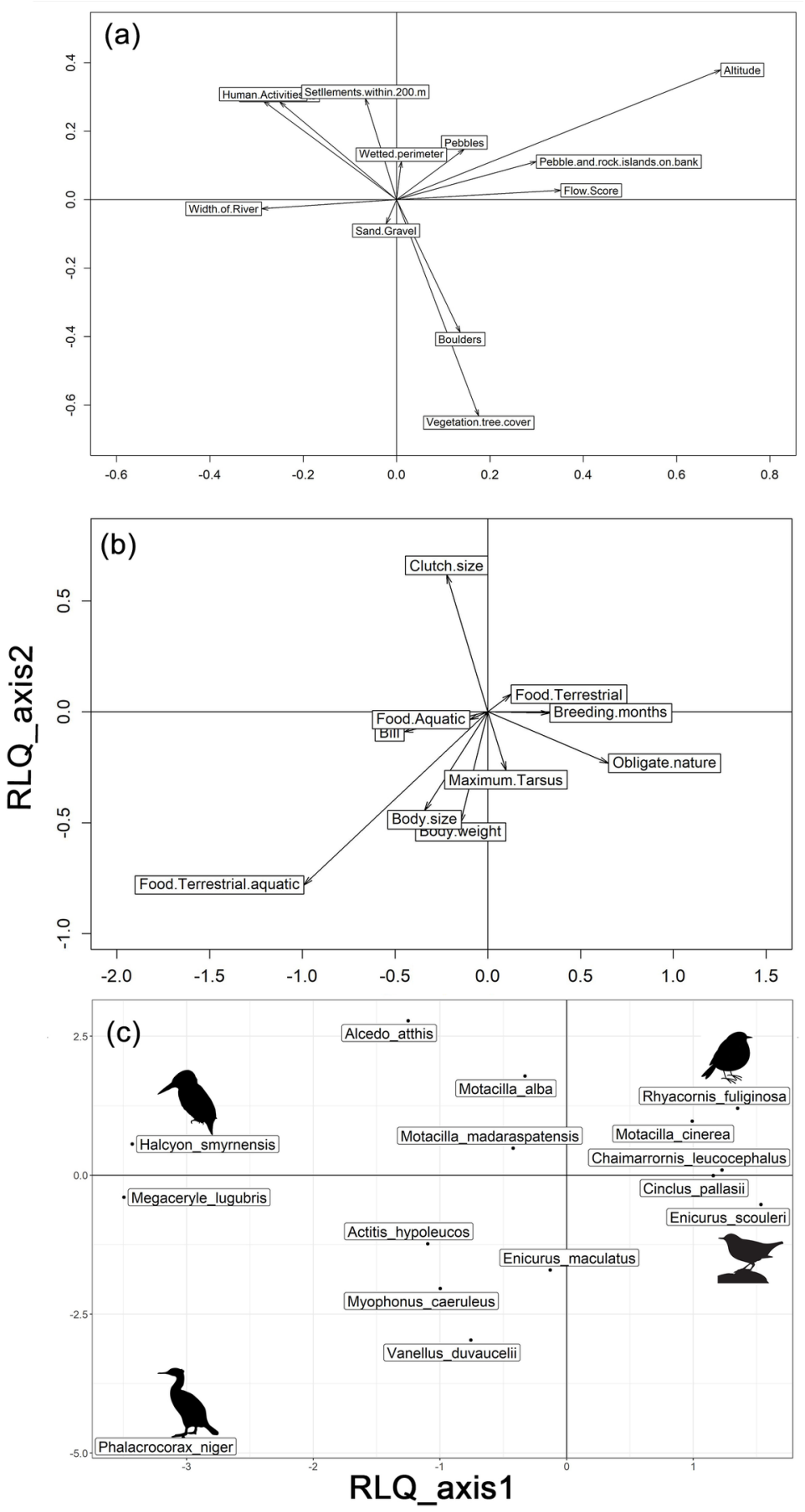


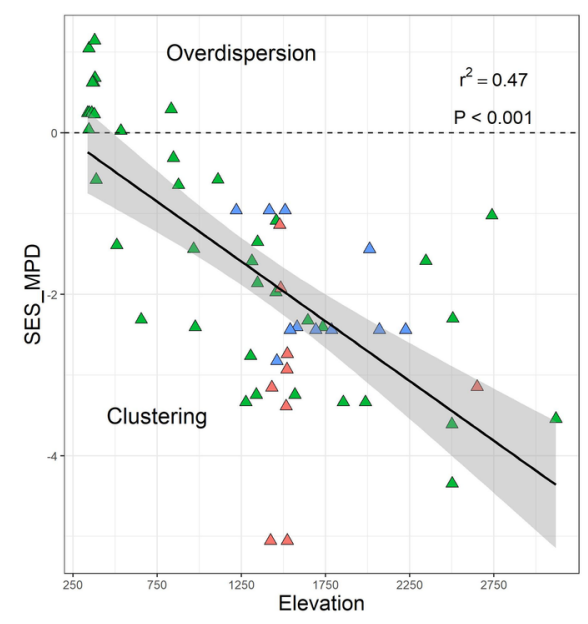

River Basin $\Delta$ Amrut Ganga $\Delta$ Bhagirathi $\Delta$ Tirthan

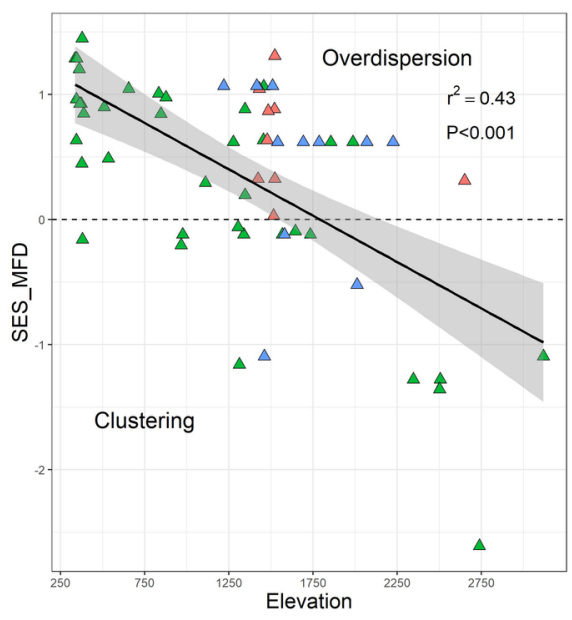

River basin $\Delta$ Amrut Ganga $\Delta$ Bhagirathi $\Delta$ Tirthan
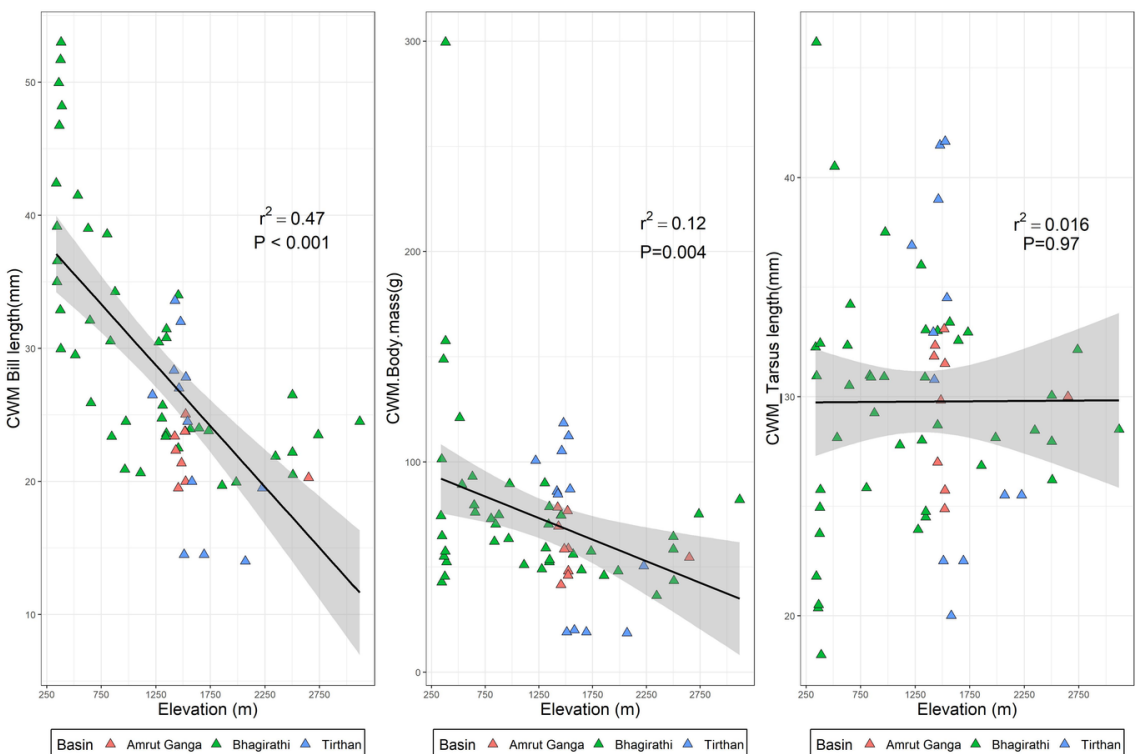